\title{
Safflower polysaccharide inhibits the proliferation and metastasis of MCF-7 breast cancer cells
}

\author{
ZHONGBING LUO ${ }^{1,2}$, HONGXIE ZENG $^{3}$, YONGQIANG YE ${ }^{2}$, LIANBIN LIU ${ }^{3}$, \\ SHAOJIN LI ${ }^{3}$, JUNYI ZHANG ${ }^{1}$ and RONGCHENG LUO ${ }^{1}$ \\ ${ }^{1}$ Department of Oncology, Cancer Center of Southern Medical University, Guangzhou, Guandong 510315; \\ Departments of ${ }^{2}$ Breast Surgery and ${ }^{3}$ Chemotherapy, Ganzhou Cancer Hospital, Ganzhou, Jiangxi 341000, P.R. China
}

Received April 17, 2014; Accepted December 12, 2014

DOI: $10.3892 / \mathrm{mmr} .2015 .3310$

\begin{abstract}
Breast cancer accounts for $22.9 \%$ of all types of cancer in females worldwide. Safflower polysaccharide (SPS) is an active fraction purified from safflower petals (Carthamus tinctorius L). The present study investigated the effects of safflower polysaccharide on the proliferation and metastasis of breast cancer cells. Cell viability was analyzed using an MTT assay following treatment of the MCF-7 cells with increasing concentrations of SPS. The results demonstrated that the SPS compound significantly inhibited the proliferation of the MCF-7 human breast cancer cell line and these inhibitory effects increased in a dose- and time-dependent manner. The half maximal inhibitory concentration $\left(\mathrm{IC}_{50}\right)$ value of SPS on breast cancer cells, following treatment for $72 \mathrm{~h}$, was detected using an MTT assay and was calculated as $0.12 \mathrm{mg} / \mathrm{ml}$. The apoptotic rate was detected using flow cytometry in the MCF-7 human breast cancer cell line and the results revealed that SPS induced cell apoptosis. The apoptotic rate of the MCF-7 cells treated with SPS was significantly higher compared with that of the untreated cells and increased in a dose-dependent manner. The expression of B-cell lymphoma 2 (Bcl-2) was downregulated and the expression of $\mathrm{Bcl}-2$-associated $\mathrm{X}$ protein was upregulated in the MCF-7 cells treated with SPS in a time-dependent manner. Additionally, the expression of matrix metalloproteinase- 9 was significantly reduced and the expression of tissue inhibitor of metalloproteinase-1 was increased in the MCF-7 human breast cancer cell treated with SPS. These results demonstrated that SPS inhibited the metastasis of MCF-7 breast cancer cells and
\end{abstract}

Correspondence to: Mr. Rongcheng Luo or Dr Junyi Zhang, Department of Oncology, Cancer Center of Southern Medical University, 13 Shiliugang Road, Guangzhou, Guangdong 510315, P.R. China

E-mail: rongchengaluo2008@163.com

E-mail: lzbuo.luo@163.com

Key words: breast cancer, safflower polysaccharide, apoptosis, metastasis understanding the underlying mechanisms may provide novel strategies in breast cancer therapy.

\section{Introduction}

Cancer is one of the most life threatening diseases in humans worldwide. Breast cancer is the most frequent type of cancer affecting western females, accounting for 7-10\% cases of systemic cancer $(1,2)$. Breast cancer is predominantly a result of abnormal division and malignant proliferation of the breast duct or acinar cells $(3,4)$. The incidence of breast cancer has increased in the majority of countries (5) and its metastasis to distant sites is the predominant cause of mortality (6). Currently, there remains no effective means to treat breast cancer. Inducing the apoptosis of tumor cells is an important strategy in cancer treatment (7-9). There are at least two pathways, which lead to cell apoptosis, an 'extrinsic' and an 'intrinsic' pathway, which are mediated by death receptors on the cell surface and by mitochondria, respectively (10-12). The intrinsic apoptotic pathway is characterized by the permeabilization of the mitochondria and the release of cytochrome $c$ into the cytoplasm $(13,14)$. Notably, the expression levels of the anti-apoptotic factor, B-cell lymphoma 2 (Bcl-2) and pro-apoptotic protein, Bcl-2-associated X protein (Bax), increase during the process of apoptosis, occurring in a mitochondria-mediated apoptotic signaling pathway $(15,16)$.

The prognosis of patients with breast cancer is closely associated with the malignant invasion and early metastasis of the cancer cells $(17,18)$. The involvement of matrix metalloproteinases (MMPs) in tumor invasion and metastases is an area of interest. The activation of MMP in the extracellular matrix degrade collagen and release growth factors and peptides $(19,20)$. Under pathological conditions, the expression of MMPs increase significantly faster compared with that of the tissue inhibitors of metalloproteinase (TIMPs), which induce the activation of MMPs, alters the tumor microenvironment and activates cell surface receptors and downstream signaling pathways (21). MMP-9 and its specific inhibitor, TIMP-1, are closely correlated with tumor physiological and pathological processes (22). Activated MMP-9 and pro-MMP-9 bind to TIMP-1, and the activation of MMP-9 is often characterized by the degradation of TIMP-1 and the accumulation of extracellular matrix $(23,24)$. Thus, MMP-9 is closely associated with 
the occurrence and development of breast cancer. Therefore, it is important to identify potential effective therapeutic agents, which can effectively activate apoptosis-mediated cell death and inhibit the invasion and metastasis of breast cancer.

Safflower (Carthamus tinctorius $\mathrm{L}$ ) is a traditional Chinese medicine. It is a herbaceous plant of the Asteraceae family and contains a variety of chemical constituents, including flavonoids, organic acids and polysaccharides (25). It has been reported that safflower polysaccharide (SPS) has an immune regulatory function, antitumor effect (25-27), may activate the phosphatidylinositide 3-kinase/Akt signaling pathways and regulate the cell cycle of cancer cells (28). However, the role of SPS on the proliferation and metastasis of breast cancer remains to be elucidated. The present study investigated the effects of SPS on the proliferation and metastasis of breast cancer cells to clarify the mechanisms underlying breast cancer and provide novel strategies for breast cancer therapy.

\section{Materials and methods}

Cells and reagents. The MCF-7 human breast cancer cell line (HTB-22 ${ }^{\mathrm{TM}}$; American Type Culture Collection, Manassas, VA, USA) was cultured in Dulbecco's modified Eagle's medium supplemented with $10 \%$ fetal calf serum (HyClone Laboratories, Inc., Logan, UT, USA). The MTT reagent was purchased from Sigma-Aldrich (St. Louis, MO, USA). Rabbit polyclonal Bcl-2 (cat. no. ab7973), rabbit polyclonal MMP9 (cat. no. ab38898) and mouse monoclonal TIMP1 (cat. no. ab1827) antibodies were purchased from Abcam (Cambridge, UK) and rabbit monoclonal Bax antibody (cat. no. AJ1079a) was obtained from Abgent (Suzhou, China).

SPS preparation. The dried red flower and leaves of the safflower (Tongrentang Co., Ltd., Beijing, China) were used to extract the polysaccharide. The dried red flower was fully impregnated into water, and was boiled four times for $1 \mathrm{~h}$ each time. The filtrate was combined and concentrated to a volume of $1 / 4$ prior to adding $95 \%$ ethanol (Jinhua Chemical Reagent Co., Ltd., Guangzhou, China) to a volume of four-five times and incubated overnight at $4^{\circ} \mathrm{C}$. The SPS was precipitated by alcohol precipitation and collected by centrifugation at $200 \mathrm{x} \mathrm{g} / \mathrm{min}$ for $5 \mathrm{~min}$. The SPS was dissolved in deionized water and the SPS was precipitated twice using ethanol. The SPS content was determined using a sulfuric acid-phenol method, as described previously (29-32), and the polysaccharide purity was up to $76.05 \%$.

MTT assay. Cell proliferation analysis was performed using an MTT assay. Briefly, the MCF-7 breast cancer cells were seeded into 96 -well plates $\left(5 \times 10^{4}\right.$ cells/well), and following adherence, the cells were treated with SPS at concentrations of $0.04,0.08,0.17,0.34,0.68$ or $1.36 \mathrm{mg} / \mathrm{ml}$ for 24,48 and $72 \mathrm{~h}$ at $37^{\circ} \mathrm{C}$. A total of $20 \mu \mathrm{l} \mathrm{MTT}(5 \mathrm{mg} / \mathrm{ml})$ was then added to the medium in each well for $4 \mathrm{~h}$ and $150 \mu \mathrm{l}$ dimethylsulfoxide was added. The absorbance of the 96-well plates was read using a microplate reader (Ultraviolet Spectrophotometer AquaMate-Plus; Thermo Fisher Scientific, Waltham, MA, USA) at a test wavelength of $490 \mathrm{~nm}$ and a reference wavelength of $570 \mathrm{~nm}$.
Western blot analysis. The breast cancer cells were seeded into 48 -well plates $\left(5 \times 10^{5}\right.$ cells/well) for $8 \mathrm{~h}$, prior to treatment with different concentrations of SPS $(0.04,0.20$ and $0.60 \mathrm{mg} / \mathrm{ml})$ for 24,48 and $72 \mathrm{~h}$. The cell lysates were prepared using sodium dodecyl sulfate (SDS) loading buffer. The lysates were separated using $10 \%$ SDS-PAGE gels and the proteins were transferred from the gel onto a nitrocellulose membrane (Biodee Corporation, Beijing, China) at $35 \mathrm{~V}$ for $3 \mathrm{~h}$ (constant voltage). The membrane was then blocked with TBST supplemented with $5 \%$ bovine serum albumin for $30 \mathrm{~min}$ prior to incubating the membrane with the specific antibodies in Tris-buffered saline with Tween-20 (TBST) containing $5 \%$ bovine serum albumin at $4^{\circ} \mathrm{C}$ overnight. The membrane was washed three times with TBST and then incubated with the goat anti-mouse IgG (SN133) and goat anti-rabbit (BA1054) secondary antibodies [Sunshine Biotechnology (Nanjing) Co., Ltd., Nanjing, China] for $1 \mathrm{~h}$ at room temperature. The bands were detected in a dark room using an Immobilon Western Chemiluminescent kit (EMD Millipore, Billerica, MA, USA).

Flow cytometric analysis. The apoptotic rates of the MCF-7 breast cancer cells were determined using annexin V-propidium iodide (PI) staining, according to the manufacturer's instructions (Santa Cruz Biotechnolgy, Inc., Dallas, TX, USA). Briefly, the cells $\left(5 \times 10^{5}\right.$ cells/well) were seeded into 6 -well plates for $6 \mathrm{~h}$ prior to treatment with SPS at the concentrations of 0.04 and $0.68 \mathrm{mg} / \mathrm{ml}$ for $48 \mathrm{~h}$. The cells were then washed and resuspended in phosphate-buffered saline (HyClone Laboratories, Inc.). Annexin V $(0.1 \mu \mathrm{g} / \mu \mathrm{l})$ and PI $(0.05 \mu \mathrm{g} / \mu \mathrm{l})$ were added to the cells and incubated in the dark for $30 \mathrm{~min}$ on ice. The apoptotic rate was determined using fluorescent activated cell sorting (FACS) analysis (FACSCalibur Cell Sorting system; BD Biosciences, Franklin Lakes, NJ, USA).

Statistical analysis. The data were analyzed using SPSS 11.5 statistical software (SPSS, Inc., Chicago, IL, USA) and the data are expressed as the mean \pm standard error of the mean. One way analysis of variance and Student's t-test were used to analyze the results. $\mathrm{P}<0.01$ was considered to indicate a statistically significant difference.

\section{Results}

SPS has an increasing antitumor effect on the MCF-7 breast cancer cell line in a time-and dose-dependent manner. In order to investigate the antitumor activity of SPS on breast cancer cells, the MCF-7 human breast cancer cell line was used and the antitumor effects of SPS were detected using an MTT assay. As shown in Fig. 1, the MCF-7 cells were treated by SPS at concentrations of $0.04,0.08,0.17,0.34,0.68$ or $1.36 \mathrm{mg} / \mathrm{ml}$. The results demonstrated that the inhibitory rates of SPS on the MCF-7 cells increased significantly as the concentration of SPS increased.

The MCF-7 cells were also treated with various concentrations of SPS for 24, 48 and $72 \mathrm{~h}$, which revealed that the antitumor effects of SPS occurred in a time-dependent manner. As shown in Fig. 1, the inhibitory rate on the breast cancer cells treated with SPS for $72 \mathrm{~h}$ was significantly higher compared with those treated for $24 \mathrm{~h}(\mathrm{P}<0.01)$ and $48 \mathrm{~h}(\mathrm{P}<0.05)$. SPS had an effective antitumor effect at the concentration of 


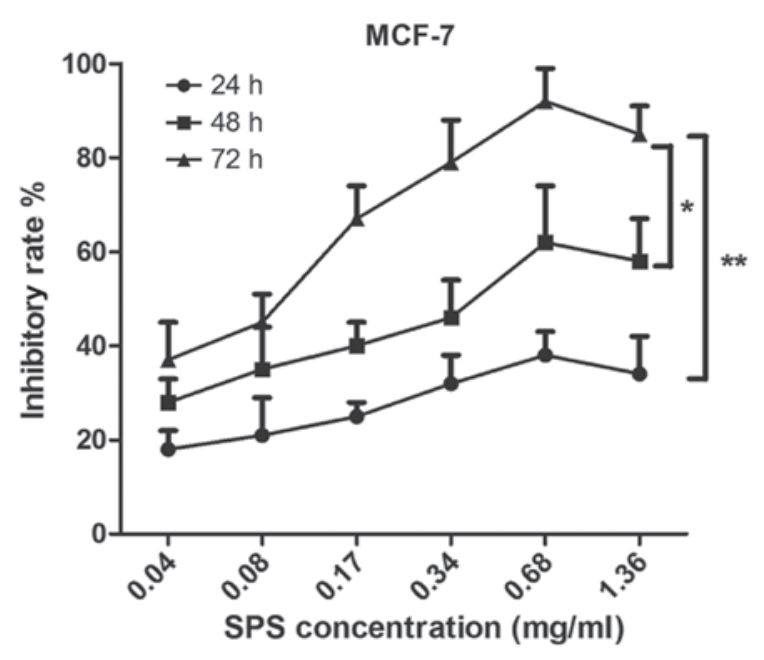

Figure 1. SPS has an increasing antitumor effect on MCF-7 breast cancer cells in a time- and dose-dependent manner. The inhibition rate of MCF-7 cells was determined using an MTT assay. The breast cancer cells $\left(2 \times 10^{4}\right.$ cells/well) were seeded into 96 -well plates and incubated with various concentrations of SPS for 24,48 or $72 \mathrm{~h}$. Untreated MCF-7 cells were used as a negative control. The data are expressed as the mean \pm standard error $\left(\mathrm{P}<0.05\right.$ and ${ }^{* *} \mathrm{P}<0.01$, as compared with the control group). SPS, safflower polysaccharide.

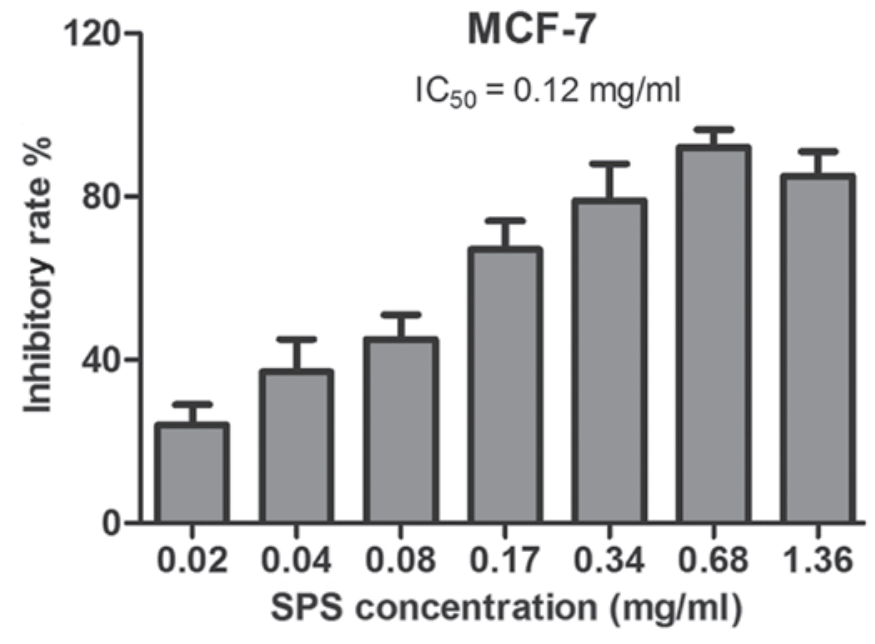

Figure 2. $\mathrm{IC}_{50}$ value of SPS on breast cancer cells treated for $72 \mathrm{~h}$. The MCF-7 cells were incubated with various concentrations of SPS for $72 \mathrm{~h}$ and the inhibitory rate of the cells was measured using an MTT assay. Untreated cells were used as a negative control. The experiment was repeated three times and the samples were treated in duplicates. The data are expressed as the mean \pm standard error. $\mathrm{IC}_{50}$, half maximal inhibitory concentration; SPS, safflower polysaccharide. ${ }^{*} \mathrm{P}<0.05,{ }^{* *} \mathrm{P}<0.01$, as compared with the control group.

$\mathbf{A}$

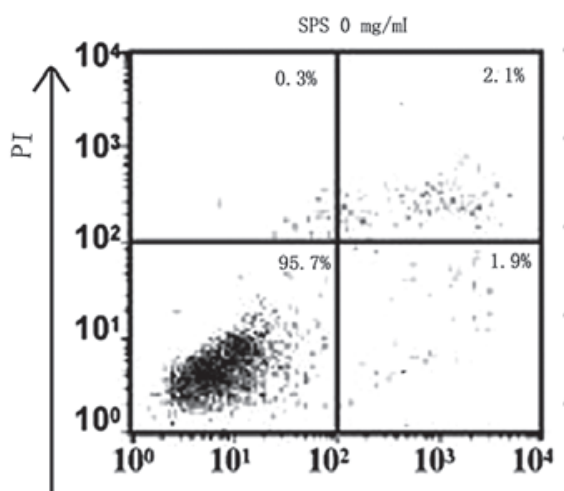

B

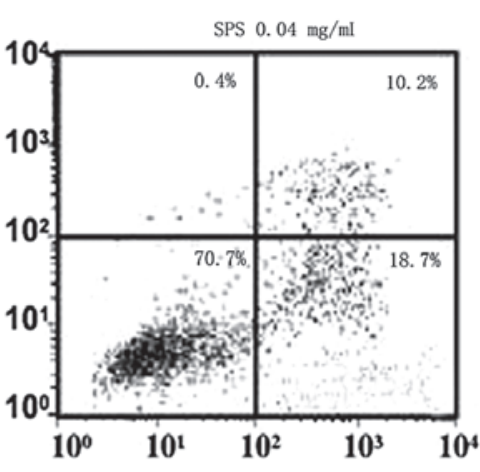

MCF-7

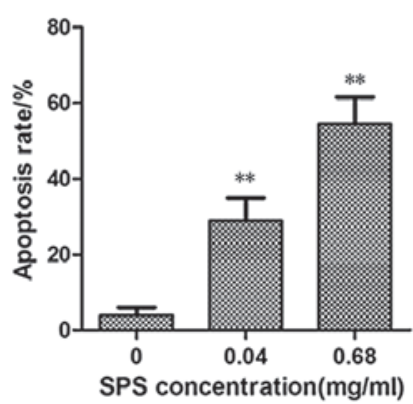

Figure 3. MCF-7 cell apoptotic rate increases with increasing concentrations of SPS. (A) Breast cancer MCF-7 cells (2x10 5 cells/well) were seeded into 6-well plates and treated with SPS $(0,0.04$ or $0.68 \mathrm{mg} / \mathrm{ml})$ following adherence. Untreated cells were used as negative controls. After $48 \mathrm{~h}$, the apoptotic rates were determined by annexin V/fluorescein isothiocyanate and PI staining analysis. (B) Histogram of the percentage of apoptotic cells. The data represent three independent experiments. SPS, safflower polysaccharide, PI, propidium iodide. ${ }^{* *} \mathrm{P}<0.01$, vs. the control group.

$0.68 \mathrm{mg} / \mathrm{ml}$ at various time points. The inhibitory rate at the concentration of $1.36 \mathrm{mg} / \mathrm{ml}$ was lower compared with that at $0.68 \mathrm{mg} / \mathrm{ml}$. These data revealed that SPS has an antitumor effect and that these inhibitory effects increased in a time- and dose-dependent manner.
Detection of the $I C_{50}$ of SPS in breast cancer cells treated with SPS for $72 \mathrm{~h}$. The duration of $72 \mathrm{~h}$ was selected as an appropriate time-point to treat the MCF-7 cells with SPS. This was repeated more than three times and all the samples were detected in duplicates. Untreated breast cancer cells were used 
A

$$
\text { Ctrl. }
$$

$24 \mathrm{~h}$

$48 \mathrm{~h}$

$72 \mathrm{~h}$

Bcl-2

Bax

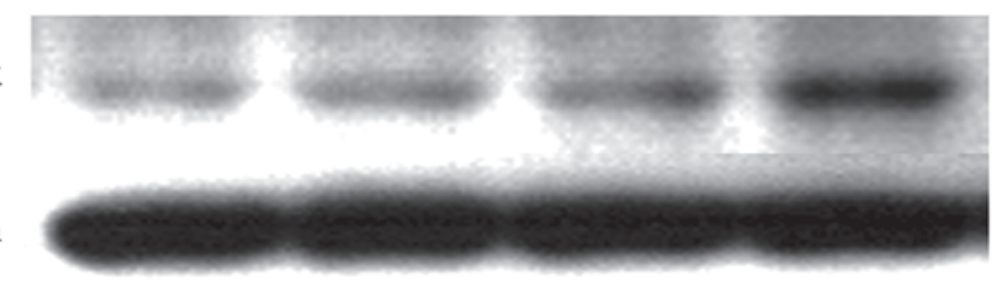

B
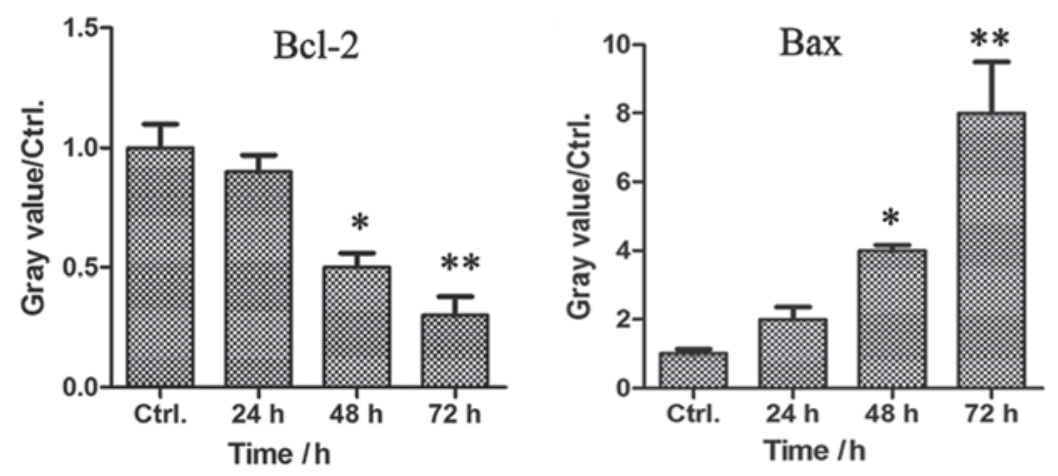

Figure 4. SPS downregulates the expression of Bcl-2 and upregulates the expression of Bax protein in the MCF-7 breast cancer cells. (A) MCF-7 breast cancer cells were seeded into 48-well plates. Following adherence, the cells were treated with SPS for 24,48 or $72 \mathrm{~h}$ at a concentration of $0.68 \mathrm{mg} / \mathrm{ml}$. Cell lysates were used to detect the expression levels of Bcl-2 and Bax by western blot analysis. $\beta$-actin was used as an internal reference. (B) Data represent the expression levels of Bcl-2 and Bax at 24, 48 and $72 \mathrm{~h}$ for at least three independent experiments. (" $\mathrm{P}<0.05$ and ${ }^{* * *} \mathrm{P}<0.01$, as compared with the control group). Ctrl, control; Bcl-2, B cell lymphoma-2; Bax, Bcl-2 associated X protein; SPS, safflower polysaccharide.

A

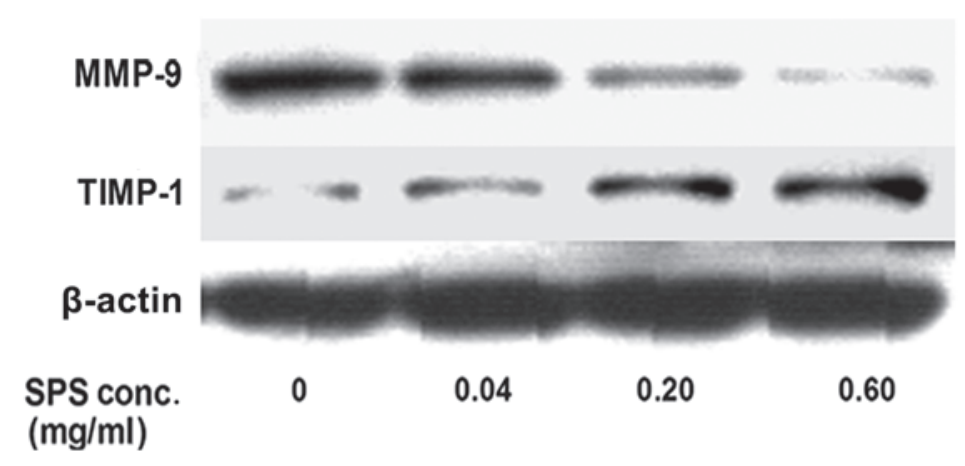

B
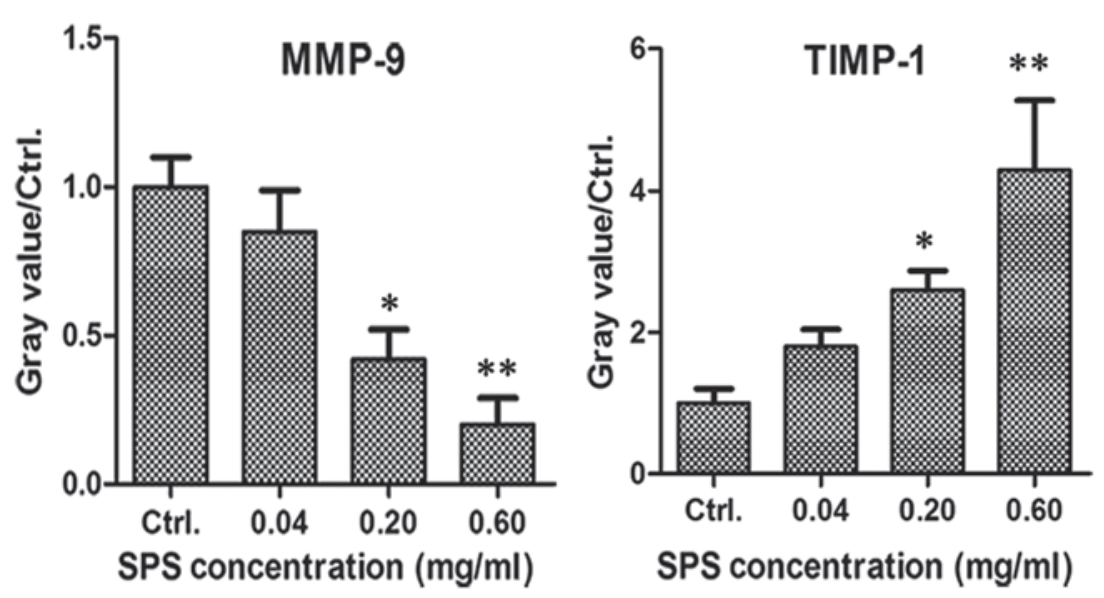

Figure 5. SPS inhibits the expression of MMP-9 and increases the expression of TIMP-1. (A) MCF-7 breast cancer cells were seeded into 48-well plates. Following adherence, the cells were treated with SPS for $48 \mathrm{~h}$ at concentrations of $0.04,0.20$ or $0.60 \mathrm{mg} / \mathrm{ml}$. The expression levels of MMP- 9 and its inhibitor, TIMP-1, were determined by western blot analysis. $\beta$-actin was used as an internal reference. (B) Data represent the expression levels of MMP-9 and TIMP-1 following treatment with various concentrations of SPS for at least two independent experiments, performed in duplicate ("P<0.05 and ${ }^{* *} \mathrm{P}<0.01$, as compared with the control group). MMP, matrix metalloproteinase; TIMP, tissue inhibitor of metalloproteinases; SPS, safflower polysaccharide; Ctrl, control. 
as a negative control. As shown in Fig. 2, the $\mathrm{IC}_{50}$ value for $72 \mathrm{~h}$ treatment was calculated as $0.12 \mathrm{mg} / \mathrm{ml}$.

MCF-7 apoptotic rate increases with increasing concentrations of SPS. The MCF-7 cell apoptotic rates were determined by FACS analysis. The MCF-7 breast cancer cell line was treated with various concentrations of SPS for $48 \mathrm{~h}$. The lowest concentration of SPS was $0.04 \mathrm{mg} / \mathrm{ml}$ and the highest concentration of SPS was $0.68 \mathrm{mg} / \mathrm{ml}$. As shown in Fig. 3, the apoptotic rates of the MCF-7 cells treated with SPS at the concentrations of 0.68 and $0.04 \mathrm{mg} / \mathrm{ml}$ were 54.5 and $28.9 \%$, respectively. As expected, the apoptotic rates of the MCF-7 breast cancer cells treated with SPS were significantly higher compared with the untreated cells. The apoptotic rates also increased in a dose-dependent manner.

SPS downregulates the expression of Bcl-2 and upregulates the protein expression of Bax in MCF-7 breast cancer cells. Cell apoptosis is induced via the extrinsic pathway and the intrinsic pathway, which are mediated by death receptors and mitochondria, respectively. In the present study, FACS analysis demonstrated that SPS induced the apoptosis of the MCF-7 cells. Subsequent investigation aimed to determine whether the SPS-induced cell apoptosis was induced by the death receptor pathway or by the mitochondria-mediated signaling pathway. The MCF-7 breast cancer cells were treated with SPS at a concentration of $0.68 \mathrm{mg} / \mathrm{ml}$ for various time-periods. The cell lysates were prepared and the protein expression levels of $\mathrm{Bcl}-2$ and Bax were detected by western blot analysis. As shown in Fig. 4, the expression of the apoptosis inhibitor, Bcl-2, reduced in a time-dependent manner, however, the expression of the apoptosis promoter, Bax, increased in the SPS-treated MCF-7 cells, suggesting that the SPS-induced cell apoptosis was dependent on the mitochondria-mediated signaling pathway.

SPS inhibits the expression of MMP-9 and increases the expression of TIMP-1. In order to investigate the role of SPS on tumor metastasis in breast cancer, the expression levels of MMP-9 and TIMP-1 were detected by western blot analysis. The MCF-7 breast cancer cells were treated with various concentrations of SPS for $72 \mathrm{~h}$ and the results demonstrated that the expression of MMP-9 was downregulated and the expression of TIMP-1 was upregulated in the SPS-treated cells at the concentration of $0.6 \mathrm{mg} / \mathrm{ml}$ (Fig. 5). All these results suggested that SPS inhibited breast cancer cell metastases.

\section{Discussion}

Breast cancer is the most common type of malignancy affecting females worldwide, with high incidence and mortality rates. Although the comprehensive treatment approach, combining surgery, radiotherapy and chemotherapy, can significantly prolong the survival rate of patients with breast cancer, it remains the most common cause of cancer-associated mortality in females (33). The recurrence and metastasis of breast cancer is the predominant cause of mortality $(34,35)$, therefore, it is important to identify an effective therapeutic approach for the treatment of breast cancer. SPS is an active ingredient extracted from safflower, which is a traditional Chinese medicine that is commonly used clinically (25). SPS has been reported to exert a variety of pharmacological effects (36) and previous studies have demonstrated that SPS exhibits antitumor activity (27), although the underlying mechanism remained to be elucidated. The present study used the MCF-7 breast cancer cell line as a breast cancer model and investigated the effects of SPS on the proliferation and metastasis of the MCF-7 cells.

An MTT assay was used to detect whether SPS inhibited the proliferation of breast cancer cells. The results demonstrated that SPS suppressed the growth and proliferation rate of the MCF-7 cells in a dose- and time-dependent manner. SPS exhibited a potent antitumor effect at a concentration of $0.68 \mathrm{mg} / \mathrm{ml}$ for 24, 48 and $72 \mathrm{~h}$. In addition, the rate of apoptosis was induced in the SPS-treated cells at a concentration of $0.68 \mathrm{mg} / \mathrm{ml}$ for $48 \mathrm{~h}$ and the expression levels of Bax and Bcl-2 were significantly increased and decreased, respectively, in the SPS treated MCF-7 cells. This suggested that SPS-induced cell apoptosis was dependent on the mitochondria-mediated signaling pathway. Tumor metastasis in breast cancer is the major cause of morality in patients with malignant tumors. The expression levels of MMP-9 and its inhibitor, TIMP-1, were also detected in the SPS-treated MCF-7 cells compared with the untreated cells. SPS significantly inhibited the expression of MMP-9 and increased the expression of TIMP-1, suggesting that SPS may suppress the invasion and metastasis of breast cancer cells.

The results of the present study may provide novel strategies for developing SPS-based therapies to treat breast cancer, which can be assisted by elucidating the mechanism underlying breast cancer.

\section{References}

1. Willis $\mathrm{K}$, Lewis S, Ng F and Wilson L: The experience of living with metastatic breast cancer-A review of the literature. Health Care Women Int 29, 1-29, 2014.

2. Libson S and Lippman M: A review of clinical aspects of breast cancer. Int Rev Psychiatry 26: 4-15, 2014.

3. Eden JA: Human breast cancer stem cells and sex hormones - a narrative review. Menopause 17: 801-810, 2010.

4. Ginossar T, De Vargas F, Sanchez C and Oetzel J: "That word, cancer": breast care behavior of Hispanic women in new Mexico background and literature review. Health Care Women Int 31: 68-87, 2010.

5. Verkooijen HM, Bouchardy C, Vinh-Hung V, Rapiti E and Hartman M: The incidence of breast cancer and changes in the use of hormone replacement therapy: a review of the evidence. Maturitas 64: 80-85, 2009.

6. Deapen D: Breast implants and breast cancer: a review of incidence, detection, mortality, and survival. Plast Reconstr Surg 120: 70S-80S, 2007.

7. Wu J: Apoptosis and angiogenesis: two promising tumor markers in breast cancer (review). Anticancer Res 16: 2233-2239, 1996.

8. Amaral C, Borges M, Melo S, da Silva ET, Correia-da-Silva G and Teixeira N: Apoptosis and autophagy in breast cancer cells following exemestane treatment. PLoS One 7: e42398, 2012.

9. Yang $\mathrm{H}$ and Dou QP: Targeting apoptosis pathway with natural terpenoids: Implications for treatment of breast and prostate cancer. Curr Drug Targets 11: 733-744, 2010.

10. Grimm D, Wehland M, Pietsch J, Infanger M and Bauer J: Drugs interfering with apoptosis in breast cancer. Curr Pharm Des 17: 272-283, 2011.

11. Elumalai P, Gunadharini DN, Senthilkumar K, et al: Induction of apoptosis in human breast cancer cells by nimbolide through extrinsic and intrinsic pathway. Toxicol Lett 215: 131-142, 2012.

12. Park H, Bergeron E, Senta H, et al: Sanguinarine induces apoptosis of human osteosarcoma cells through the extrinsic and intrinsic pathways. Biochem Biophys Res Commun 399: 446-451, 2010.

13. Li Y, He K, Huang Y, et al: Betulin induces mitochondrial cytochrome c release associated apoptosis in human cancer cells. Mol Carcinog 49: 630-640, 2010. 
14. Chen FP and Chien MH: Phytoestrogens induce apoptosis through a mitochondria/caspase pathway in human breast cancer cells. Climacteric 17,385-389, 2014.

15. Aiyar SE, Park H, Aldo PB, et al: TMS, a chemically modified herbal derivative of resveratrol, induces cell death by targeting Bax. Breast Cancer Res Treat 124: 265-277, 2010.

16. Boohaker RJ, Zhang G, Lee MW, et al: Rational development of a cytotoxic peptide to trigger cell death. Mol Pharm 9: 2080-2093, 2012.

17. Wang XX, Cheng Q, Zhang SN, et al: PAK5-Egr1-MMP2 signaling controls the migration and invasion in breast cancer cell. Tumour Biol 34: 2721-2729, 2013.

18. Zu X, Zhang Q, Cao R, et al: Transforming growth factor-beta signaling in tumor initiation, progression and therapy in breast cancer: an update. Cell Tissue Res 347: 73-84, 2012

19. Folgueira MA, Maistro S, Katayama ML, et al: Markers of breast cancer stromal fibroblasts in the primary tumour site associated with lymph node metastasis: a systematic review including our case series. Biosci Rep 33: e00085, 2013.

20. Jezierska A and Motyl T: Matrix metalloproteinase-2 involvement in breast cancer progression: a mini-review. Med Sci Monit 15: RA32-RA40, 2009.

21. Nyormoi O, Mills L and Bar-Eli M: An MMP-2/MMP-9 inhibitor, $5 \mathrm{a}$, enhances apoptosis induced by ligands of the TNF receptor superfamily in cancer cells. Cell Death Differ 10: 558-569, 2003

22. Sun Y, Lu N, Ling Y, et al: Oroxylin A suppresses invasion through down-regulating the expression of matrix metalloproteinase-2/9 in MDA-MB-435 human breast cancer cells. Eur J Pharmacol 603: 22-28, 2009.

23. Lewandowska U, Szewczyk K, Owczarek K, et al: Flavanols from Japanese quince (Chaenomeles japonica) fruit inhibit human prostate and breast cancer cell line invasiveness and cause favorable changes in Bax/Bcl-2 mRNA ratio. Nutr Cancer 65 : 273-285, 2013

24. Li F, Li C, Zhang H, et al: VI-14, a novel flavonoid derivative, inhibits migration and invasion of human breast cancer cells. Toxicol Appl Pharmacol 261: 217-226, 2012.

25. Wakabayashi T, Hirokawa S, Yamauchi N, Kataoka T, Woo JT and Nagai K: Immunomodulating activities of polysaccharide fractions from dried safflower petals. Cytotechnology 25: 205-211, 1997.
26. Ando I, Tsukumo Y, Wakabayashi T, et al: Safflower polysaccharides activate the transcription factor NF-kappa B via Toll-like receptor 4 and induce cytokine production by macrophages. Int Immunopharmacol 2: 1155-1162, 2002.

27. Shi X, Ruan D, Wang Y, Ma L and Li M: Anti-tumor activity of safflower polysaccharide (SPS) and effect on cytotoxicity of CTL cells, NK cells of T739 lung cancer in mice. Zhongguo Zhong Yao Za Zhi 35: 215-218, 2010 (In Chinese).

28. Chen L, Xiang Y, Kong L, et al: Hydroxysafflor yellow A protects against cerebral ischemia-reperfusion injury by anti-apoptotic effect through PI3K/Akt/GSK3 $\beta$ pathway in rat. Neurochem Res 38: 2268-2275, 2013.

29. Lin FM and Pomeranz Y: Effect of borate on colorimetric determinations of carbohydrates by the phenol-sulfuric acid method. Anal Biochem 24: 128-131, 1968.

30. Masuko T, Minami A, Iwasaki N, Majima T, Nishimura S and Lee YC: Carbohydrate analysis by a phenol-sulfuric acid method in microplate format. Anal Biochem 339: 69-72, 2005.

31. Saha SK and Brewer CF: Determination of the concentrations of oligosaccharides, complex type carbohydrates, and glycoproteins using the phenol-sulfuric acid method. Carbohydr Res 254: 157-167, 1994.

32. Cuesta G, Suarez N, Bessio MI, Ferreira F and Massaldi H: Quantitative determination of pneumococcal capsular polysaccharide serotype 14 using a modification of phenol-sulfuric acid method. J Microbiol Methods 52: 69-73, 2003.

33. Siponen ET, Joensuu H and Leidenius MH: Local recurrence of breast cancer after mastectomy and modern multidisciplinary treatment. Acta Oncol 52: 66-72, 2013.

34. Koscielny S and Tubiana M: The link between local recurrence and distant metastases in human breast cancer. Int J Radiat Oncol Biol Phys 43: 11-24, 1999.

35. Dian D, Straub J, Scholz C, et al: Influencing factors for regional lymph node recurrence of breast cancer. Arch Gynecol Obstet 277: 127-134, 2008.

36. Hristov AN, Kennington LR, McGuire MA and Hunt CW: Effect of diets containing linoleic acid- or oleic acid-rich oils on ruminal fermentation and nutrient digestibility, and performance and fatty acid composition of adipose and muscle tissues of finishing cattle. J Anim Sci 83: 1312-1321, 2005. 